DR. YINZONG XIAO (Orcid ID : 0000-0001-8360-5352)

DR. NICK SCOTT (Orcid ID : 0000-0002-9213-0798)

PROF. MARGARET HELLARD (Orcid ID : 0000-0002-5055-3266)

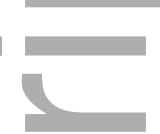

Article type : Original Paper

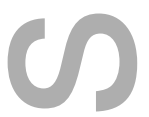

$(2)$

\title{
Enhancing the hepatitis B care cascade in Australia: a cost- effectiveness model
}

Cost effectiveness of enhancing the hepatitis B care cascade in Australia (running title)

Yinzong Xiao

85 Commercial Rd

Melbourne, VIC 3004 AUSTRALIA

yinzong.xiao@burnet.edu.au

Burnet Institute, St Vincent's Hospital Melbourne, and University of Melbourne

Jessica Howell

Burnet Institute, St Vincent's Hospital Melbourne, University of Melbourne, and Monash

University

Caroline van Gemert

Burnet Institute, and Melbourne School of Population and Global Health, University of Melbourne

This is the author manuscript accepted for publication and has undergone full peer review but has not been through the copyediting, typesetting, pagination and proofreading process, which may lead to differences between this version and the Version of Record. Please cite this article as doi: $10.1111 /$ JVH.13252

This article is protected by copyright. All rights reserved 
Alexander J. Thompson

Department of Gastroenterology, St. Vincent's Hospital Melbourne, and the University of Melbourne

\section{Christopher P. Seaman}

Burnet Institute, and Monash University

\section{Karen McCulloch}

WHO Collaborating Centre for Viral Hepatitis, Victorian Infectious Diseases Reference Laboratory, The Peter Doherty Institute for Infection and Immunity, and University of

Melbourne

Nick Scott

Burnet Institute and Monash University

Margaret E. Hellard

Burnet Institute; Department of Infectious Diseases, Alfred Hospital; School of Population Health, Monash University; Doherty Institute and Melbourne School of Population and Global Health, University of Melbourne

NS and MH should be considered joint senior author.

\section{ACKNOWLEDGEMENT}

The authors wish to acknowledge operational support through Victorian Operational Infrastructure Support Program received by Burnet Institute. NS received unrelated research grants from Gilead Sciences. JH, AJT, and MH receives unrelated investigator-initiated research grants from Gilead Sciences, AbbVie, Merck/MSD, and Bristol Myers Squibb. JH, AJT and MH receive fellowship support from Australian National Health and Medical Research Council. CVG is supported by an NHMRC Early Career Researcher Fellowship. YX is supported by the Melbourne Research Scholarship. CS receives support through an Australian Government Research Training Program scholarship. KM is funded through the Blood Borne Viruses and Sexually Transmissible Infections Surveillance and Research Programme, Australian Department of Health. 


\section{ABSTRACT AND KEYWORDS}

If Australia is to successfully eliminate hepatitis B as a public health threat it will need to enhance the chronic hepatitis B (CHB) care cascade. This study used a Markov model to assess the impact, cost and cost-effectiveness of scaling up CHB diagnosis, linkage to care and treatment to reach national and international elimination targets for hepatitis B in Australia. Compared to continued current trends, the model calculated the difference in care cascade projection, disability-adjusted life-years (DALYs), costs, and the incremental cost-effectiveness ratio (ICER), of scaling up CHB diagnosis, linkage to care and treatment to reach: (1) Australia's 2022 national targets; and (2) the WHO's 2030 global targets. Achieving the national and WHO targets had ICERs of $A \$ 13,435(A \$ 10,236-A \$ 21,165)$ and $A \$ 14,482(A \$ 13,031-A \$ 25,641)$ per DALY averted between 2016 and 2030 in Australia, respectively. However, this excluded implementation and demand generation costs. The ICER for the National Strategy and WHO Strategy remained under $\mathrm{A} \$ 50,000$ per DALY averted if Australia spent up to $\mathrm{A} \$ 328$ or $\mathrm{A} \$ 538$ million, respectively, per annum (for 2016-2030) on implementation and demand generation activities. Sensitivity analysis showed that cost-effectiveness was predominately driven by the cost of $\mathrm{CHB}$ treatment and influenced by disease progression rates. Hence for Australia to reach the National Hepatitis B Strategy 2022 targets and WHO Strategy 2030 targets it requires an improvement in the $\mathrm{CHB}$ care cascade. We estimated it is cost-effective to spend up to $\mathrm{A} \$ 328$ million or A $\$ 538$ million per year to reach the National and WHO Strategy targets, respectively.

\section{Keywords}

Hepatitis B

Care cascade

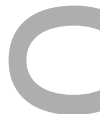

Cost-effectiveness analysis

\section{INTRODUCTION}

Chronic hepatitis B (CHB) continues to be a major global health threat: approximately 292 million people were infected with hepatitis B virus (HBV) in 2016 [1] and an estimated 887,000 deaths were attributed to HBV-associated liver disease in 2015 [2]. Decompensated cirrhosis (DC) and hepatocellular carcinoma (HCC) are the most severe outcomes of CHB [2]. Around 20\% 
of people living with $\mathrm{CHB}$ will develop cirrhosis if untreated [3], and $\mathrm{CHB}$ increases the risk of developing HCC between 5 and 100-times compared to unaffected individuals [4]. Although there is no current curative therapy for $\mathrm{CHB}$, treatment with nucleos $(\mathrm{t})$ ide analogues can significantly attenuate disease progression, and reduce HCC risk by between $30 \%$ and $80 \%$ [5]. Timely diagnosis, monitoring and treatment of eligible individuals [6-8] living with CHB can substantially reduce HBV-induced liver related morbidity and mortality.

In 2017, the estimated prevalence of CHB was 1\% in Australia (approximately 233,947 people) [9]. Australia has a mature healthcare system that provides fully subsidised diagnostic testing and $\mathrm{CHB}$ care, and partially subsidised medication for all Australian citizens. Despite this, modelled estimates suggest that amongst people living with CHB in Australia in 2017: approximately 36\% were undiagnosed, $80 \%$ were not in care [9], and only $26 \%$ of patients eligible for treatment based on Australian national guidelines, were receiving antiviral therapy; this was $8 \%$ of the total number of people living with CHB [9-11].

To eliminate viral hepatitis as a major public health threat by 2030, the WHO released its firstever Global Health Sector Strategy on Viral Hepatitis (hereafter referred to as the WHO Strategy) [12] in 2016. The WHO Strategy set the targets of diagnosing $90 \%$ of people living with CHB, treating $80 \%$ of those eligible and reducing HBV-related deaths by $65 \%$ by 2030 . In 2018 , the Australian government's $3^{\text {rd }}$ National Hepatitis B strategy (hereafter referred to as the National Strategy) [13] set shorter term targets, aiming to achieve $80 \%$ of people living with $\mathrm{CHB}$ diagnosed, $50 \%$ of people living with CHB linked in care, $20 \%$ of people living with CHB treated and HBV-attributable mortality to be reduced by $30 \%$ by 2022 .

Despite proportional increases in diagnoses, care engagement and treatment among people living with CHB since 2011[10], modelling data [10 14] suggested that current diagnosis rates remain insufficient for Australia to reach the National Strategy or WHO Strategy targets. This suggests further scale up of testing, linkage to care and treatment is required, but such activities come at a cost. To date, the cost and cost-effectiveness of such a scale-up is unknown as no evaluation has been undertaken to measure these costs in Australia.

This study uses a Markov model to assess the cost-effectiveness of enhanced hepatitis B care strategies in Australia. Clinical and economic outcomes were measured under three different HBV strategies: 1) continued current practice; 2) testing, linkage to care and treatment scale-up to reach the National Strategy targets and 3) the WHO Strategy targets. In particular, we estimated the cost of testing, care and treatment associated with reaching both sets of targets, 
and determined a threshold annual budget that, if invested by Australia in auxiliary interventions to improve the HBV care cascade, would keep the overall strategies under a cost-effectiveness threshold.

\section{MATERIAL AND METHODS}

\section{The model}

We simulated the CHB disease and care cascade progression among all people living with $\mathrm{CHB}$ in Australia between 2016 and 2030 using a Markov model (Figure 1). The model included four exclusive health states (CHB, compensated cirrhosis (CC), DC, and HCC) and three exclusive care cascade states ('undiagnosed', 'diagnosed with CHB but not in care', and 'in care'). People with CHB in care could be on treatment or not on treatment depending on their eligibility.

The model was initialised according to disease and care cascade distributions for Australia in 2016 [11]. At each time step, representing one year, people could:

1) enter the model (e.g. when migrating to Australia with $\mathrm{CHB}$ or when acquiring $\mathrm{CHB}$ infection);

2) progress through the different disease stages (according to age, sex and ethnicityweighted progression rates);

3) move through the care cascade (with rates estimated from a time-series of crosssectional Australian care cascade estimates);

4) clear their virus (surface antigen loss);

5) leave the model due to death (from either an age-weighted all-cause mortality or HBVattributable mortality).

\section{Calibration}

Calibration was against HBV-related deaths and incidence of HBV-related HCC, which are key indicators of $\mathrm{CHB}$ disease burden. Disease progression parameters in our study were scaled to fit the calibration target of $\mathrm{HBV}$-related deaths data, which were estimated to be 419- 504 per year in 2015- 2017 in Australia[10 11], and HBV-related HCC incidence predictions in Australia for 2017- 2021, sourced from Australian Institute of Health and Welfare[15] reports (with 22\% assumed to be attributed by HBV infection[16]). 


\section{Input parameters for the model}

\section{Study population}

The study population was all people living with CHB in Australia. Previous modelling estimated that 215,264 to 237,894 people were living with CHB in Australia in 2016[10 14 17]. The model was initialised assuming $63.5 \%$ of people living with CHB were diagnosed (45.9\% without care and $17.6 \%$ with care), sourced from modelled data [ $\left.\begin{array}{llll}9 & 14 & 17\end{array}\right]$ which was estimated from Australian census data, hepatitis B surveillance system and national health care/medication subsidy program (Table s4). Health state distributions were assumed to be different for those in care and not in care. For people living with $\mathrm{CHB}$ not in care, we assumed $97.8 \%$ did not have cirrhosis, $1.9 \%$ had CC, $0.1 \%$ had DC and $0.2 \%$ had HCC, mainly based on a Victorian community $\mathrm{CHB}$ cohort with non-invasive fibrosis assessment data [18]. For people living with CHB in care, we assumed $91.7 \%$ of people living with $\mathrm{CHB}$ did not have cirrhosis, $6.9 \%$ had CC, $1 \%$ had DC and $0.4 \%$ had HCC, based on the same study but using the hospital-based CHB cohort data, as well as unpublished hospital-based cohort data of 2,032 CHB patients attending liver clinics from St Vincent's Hospital (Melbourne, Victoria). These inputs are detailed in the supplement, Table s3.

People living with CHB in Australia are of mixed age, sex and ethnicity (Table s2), and so disease progression and mortality parameters were weighted accordingly. In 2016, an estimated $38.8 \%$ of people with CHB were born in Asia, 3.5\% were born in Sub-Saharan Africa and 10.6\% were Aboriginal and Torres Strait Islanders [17]. We assumed the sex ratio of people with CHB was 1:2 (female to male) based on sex-specific seroprevalence in CHB cohorts and the range of female proportion $(25 \%-50 \%)$ was tested in sensitivity analysis [18 19]. The age structure of people with CHB was based on modelled estimates of the age-specific $\mathrm{CHB}$ prevalence in Australia in 2016 [14 20], with the weighted average being 43 years. We assumed that the age, gender and ethnicity of the open cohort would stay the same between 2016 and 2030, with this assumption tested in sensitivity analysis.

\section{Disease progression parameter}

Parameters of CHB progression and HBV-related mortality (Table 1) were sourced from a literature search and mainly generated from three reviews [21-23] and recent studies with reasonable sample size and follow-up time. As older age, male gender and being Asian or African were associated with increased risks of progression to cirrhosis and HCC occurrence [21 22], 
relevant disease progression parameters were weighted by age, sex and ethnicity according to the study population characteristics (see supplement, Table s5).

\section{Costs}

We took the healthcare funders' perspective and assessed direct medical costs, including the average use of medical services, provider time and medicines for people in each model compartment (Table 2). For people diagnosed with CHB but not in care, we recorded the onceoff costs of diagnosing CHB. We assumed that people in care received standard care based on the Gastroenterological Society of Australia guidelines [8]. For CHB and CC management, when the standard care guidelines included multiple medical procedure options or different pathways, we recorded the cost range for the uncertainty analysis and consulted a study steering group composed of medical professionals to obtain best estimate values. We chose to model with the medication use of Entecavir and Tenofovir disoproxil fumarate based on local prescribing patterns [11], assuming life-long treatment until HBsAg loss, no drug resistance and no adverse effects.

The costs of medicine and medical services were sourced from the Pharmaceutical Benefits Scheme (PBS) [24] and Medicare Benefits Schedule (MBS) [25] respectively. We collected the costs of each item, as reported in December 2018, and used an ingredients-based approach to estimate the total annual costs incurred by a person in each compartment, in addition to a onceoff diagnosis cost where appropriate. All costs were reported in 2018 Australian dollars (AUD) and a $5 \%$ discounting rate was applied for any past or future costs as per national guidelines on discounting in health economic evaluations [26].

\section{Scenarios}

Baseline

Model baseline was a continuation of current practice within Australia. Annual probabilities of being diagnosed and linked to care were estimated by comparing the care continuum from 20152017 national surveillance reports [11] (Table s1). The annual probabilities of being diagnosed were assumed to be the same in undiagnosed people with $\mathrm{CHB} / \mathrm{CC} / \mathrm{HCC}$ but people with DC were assumed to be diagnosed and linked to care immediately. We assumed that people with CC/DC/HCC were linked to care once being diagnosed. People diagnosed with CHB (without complications) may or may not link to care; we estimated a linkage to care rate from the national surveillance reports that was applied across the $\mathrm{CHB} / \mathrm{CC} / \mathrm{HCC}$ stages, and assumed immediate 
linkage to care if progressing to DC. People with $\mathrm{CHB}$ in care who were ineligible for treatment were assumed to become eligible and receive treatment at an annual rate of 7\%-12\% [27 28], which translated to a net rate of 3\% (1\%-10\%) transiting from the ineligible to eligible compartment after accounting for treatment drop-off [29] (Figure 1). The status-quo projection assumed that these annual rates of care cascade transition remained constant in the study timeframe. The range of the estimated annual transition rates were tested in sensitivity analysis.

\section{Scale-up to reach targets}

Two scenarios were tested and compared against continued current practice: the National Strategy and the WHO Strategy. In each scenario, annual probabilities of being diagnosed and linked to care were increased until they were sufficient to meet the strategy targets (Table s1). This was defined as ' $80-50-20$ ' by 2022 for the National Strategy. However, the WHO Strategy does not include a target for linkage to care coverage, so this was estimated to be $85 \%$ (among all people living with $\mathrm{CHB}$ ) to be consistent with previous global modelling study [30], which used a target of $95 \%$ of the diagnosed population to be linked to care. Thus, the WHO strategy targets were interpreted as' $90-85$ - 80 ”' by 2030 , where the final ' 80 ' refers to $80 \%$ eligible people with $\mathrm{CHB}$ on treatment. The parameters used in each scenario are detailed in the supplement (Table s1).

\section{Outcomes}

We compared the projection of the $\mathrm{CHB}$ care continuum, total annual costs and HBV-related disability-adjusted life years (DALYs). Disability weight for disease stages were obtained from the 2017 Global Burden of Disease study [31] (Table 2). The average age of people with CHB in Australia in 2016 was used to estimate years of life lost due to HBV-related death. DALYs were discounted at $5 \%$ annually [26].

\section{Cost-effectiveness}

The incremental cost-effectiveness ratios (ICERs; cost per DALY averted) were calculated for each of the target scenarios compared to continued current trends, with a threshold of $A \$ 50,000$ per DALY averted used to assess the cost-effectiveness of the strategy.

Each strategy modelled only included the direct medical costs and did not include the costs of the demand generation activities that would be required to achieve the necessary improvements in diagnosis and treatment (as they are unknown). Therefore, a threshold annual budget was 
calculated, that if spent on these activities would leave each strategy under the $A \$ 50,000$ per DALY averted cost-effectiveness threshold (if applicable).

\section{Uncertainty and sensitivity analysis}

Confidence intervals (CIs) for projected outcomes were generated using a probabilistic uncertainty analysis. One thousand sets of parameter values were obtained by randomly sampling each parameter from its individual uncertainty range, using either uniform, normal or beta distributions as shown in Table s10. CIs were taken as the interquartile range of the corresponding model runs.

One-way deterministic sensitivity analysis was used to test the effects of single parameter variations on the ICER of the two interventional strategies, and the annual budget able to be spent on demand generation/implementation activities while remaining cost-effective. Specifically, we tested when disease progression parameters, costs and disability weights took their lower or upper bound values, and when the average age of people with CHB was 20-60 years old. The different health states distribution of people with/without care was also tested. We further tested a range of annual probabilities of being diagnosed (0-10\%) and linked to care $(0-10 \%)$ under the status-quo to reflect uncertainties in these estimates over time.

\section{RESULTS}

Under a base assumption that $5.7 \%$ of undiagnosed individuals with $\mathrm{CHB} / \mathrm{CC} / \mathrm{HCC}$ were diagnosed each year and annual net rate of care linkage of 3.3\% (Table s1), the status-quo scenario projected that by $2030,69 \%$ of people living with $\mathrm{CHB}$ were diagnosed, $30 \%$ of people living with $\mathrm{CHB}$ were in care and 18\% were receiving treatment (Figure 2). The accumulated direct medical costs of status quo scenario in 2016-2030 was A $\$ 1.7$ billion, with 1.1 million DALYs incurred (Table 3).

To reach the National Strategy targets by 2022, the model estimated that annual rates of diagnosis and linkage to care of $16.5 \%$ per year and $16 \%$ per year respectively would be required (Table s1). Enhancing the hepatitis B care cascade to achieve the National Strategy targets was projected to lead to $86 \%$ of people with CHB diagnosed in 2030 , slightly short of the WHO 2030 elimination target (Figure 2). Under the National Strategy scenario, an estimated 69\% of people living with $\mathrm{CHB}$ were linked to care and $37 \%$ of people living with $\mathrm{CHB}$ were receiving treatment by 2030 (Table 3). Total medical costs of the National Strategy scenario were estimated 
to be $\mathrm{A} \$ 3$ billion ( $\mathrm{\$} \$ 1.3$ billion more than status-quo); and there were an estimated 1.02 million DALYs between 2016-2030 (97,743 DALYs less than status quo). The ICER of enhancing the hepatitis B care cascade to achieve the National Strategy was A $\$ 13,435 /$ DALY averted (20162030) (Table 3).

The scenario aiming to reach WHO Strategy targets by 2030 led to a care cascade of $85 \%, 76 \%$ and 32\% in diagnosis, linkage to care and treatment among people living with CHB by 2022 (Figure 2), sufficient to reach the National Strategy targets. To achieve the WHO Strategy target of diagnosing $90 \%$ people by 2030 , a scale-up of annual diagnosis rate among people with $\mathrm{CHB} / \mathrm{CC} / \mathrm{HCC}$ to $24.5 \%$ per year was necessary, i.e. an approximately 4 -fold increase of annual diagnosis rate from the status quo (Table s1). Total medical costs of WHO Strategy scenario were estimated to be $\mathrm{A} \$ 4.1$ billion ( $\mathrm{A} \$ 2.4$ billion more than status quo); and there were an estimated 0.95 million DALYs between 2016-2030 (165,134 DALYs less than status quo). The ICER of enhancing the hepatitis B care cascade to achieve the WHO Strategy was A $\$ 14,482 /$ DALY averted (2016-2030) (Table 3).

The total costs of each scenario only included medical costs incurred by the cohort; it didn't include costs of programs to have more people diagnosed and linked to care, i.e. the implementation costs of care cascade scale-up, as these costs are unknown. Thus, we used the model to estimate the threshold of willingness to pay for these implementation activities. The model estimated that if an annual amount of less than $A \$ 328$ million was spent on programs to achieve the National Strategy or A $\$ 538$ million for WHO Strategy, then the overall ICERs would remain under $A \$ 50,000 /$ DALY averted (Table 3).

One-way sensitivity analyses showed that several key parameters affected the estimated ICERs of the National Strategy and WHO strategy (Figure 3). The annual probability of progressing from CHB to CC had the largest impact on both ICERs: when this probability was as low as $0.05 \%$ per annum (compared to base estimates of 1.5\%), the ICER of National Strategy and WHO Strategy were as high as A $\$ 27,671 /$ DALY averted and A $\$ 29,505 /$ DALY averted, respectively. Average age of the cohort also affected both ICERs, with both strategies being more costeffective for a younger cohort. The cost of $\mathrm{CHB}$ treatment was another key parameter affecting the cost-effectiveness of care cascade scale-up strategies: if the overall costs of treating CHB was $A \$ 799$ per person per annum (compared to base estimates of $A \$ 3,985)$, the ICERs of the National Strategy and WHO Strategy were reduced to A $\$ 7,351-7,484 /$ DALY averted. All other parameters analysed in sensitivity analysis are detailed in the supplement (Table s13). 


\section{DISCUSSION}

This is the first study to analyse the requirements to reach national and global hepatitis B service coverage targets and the potential cost-effectiveness of reaching these targets in Australia. Our model shows that the current rates of $\mathrm{CHB}$ diagnosis, care linkage and treatment would not enable Australia to meet the National strategy or WHO targets. Using A $\$ 50,000 /$ DALY averted as the willingness-to-pay threshold, scaling up the hepatitis B care cascade to reach the National Strategy targets by 2022 or WHO Strategy targets by 2030 was cost-effective. Up to $A \$ 328$ million or A $\$ 538$ million per year spent on implementation and demand generation would maintain the overall National and WHO strategies being cost-effective, respectively. The model provides economic evidence to support a greater hepatitis B public heath response in Australia.

A key finding was that Australia will struggle to meet the national and global hepatitis B service coverage targets if the status quo continues. This finding is consistent with a recent modelling report [10] that suggested Australia would not reach the WHO diagnosis and treatment coverage targets until 2059 and 2048, respectively, under current practice.

The model also suggested that the ICERs of the National Strategy scenario and WHO Strategy scenario were both below A $\$ 50,000 /$ DALY averted, the conventional upper limit of cost effectiveness thresholds. The cost-effectiveness of both strategies was significantly affected by the cost of $\mathrm{CHB}$ treatment. The first-line treatments for $\mathrm{CHB}$, entecavir and tenofovir, currently cost an average of $A \$ 2,000-5,000$ per person per annum in Australia which is higher than in most countries. Tenofovir is now off patent in many countries including high-income countries, with reported annual costs ranging from US $\$ 400$ to US $\$ 1,500$ [2]. Entecavir came off patent earlier than Tenofovir in most countries with the generic Entecavir price ranging globally from US\$430 to US\$6,127 [32]. However even these prices are high with the actual production of entecavir estimated to cost as low as US $\$ 36$ per person-year [32]. Given treatment cost impacted the cost-effectiveness in the model, this suggests that a significant reduction in the cost of treatment would concordantly improve the cost-effectiveness of the scale-up of the CHB care cascade. For Australia, as both Entecavir and Tenofovir are listed in the PBS, which means that because the government subsidises the cost of medicine, the cost-effectiveness of scaling up the hepatitis B care cascade would be markedly improved through government negotiations on drug price.

The model suggested if up to $A \$ 328$ million of $A \$ 538$ million per annum was to be spent on the implementation of the National strategy or WHO strategy over a 15-year period, respectively, the 
ICERs would remain under A $\$ 50,000$ per DALY averted. Future studies are needed to identify what demand generation and outreach interventions are required to improve the care cascade and the cost and cost effectiveness of this, in order to assess how this funding, if available, could be spent to achieve the targets.

Even though both strategy scenarios were cost-effective, the costs to achieve the national and international targets were considerable: an additional $\mathrm{A} \$ 1.3$ billion or $\mathrm{A} \$ 2.4$ billion investment over the status quo is required for CHB management over a 15-year period, approximately 0.71.3\% of Australia's 2016-2017 annual national health expenditure [33]. However, as well as being cost-effective, this additional spending on CHB management will most likely save additional future costs not captured in this model, such as costs from work productivity loss and costs of managing liver disease that were averted over a longer timeframe [34].

It should be noted that our model estimations were conservative, and the strategies are likely to be more cost-effective than we estimated, for several reasons. First, there has been a changing epidemiology of $\mathrm{CHB}$ due to the changing ethnicity structure of people living with $\mathrm{CHB}$ in Australia over time, for example the proportion of people migrating from Asia and Sub-Saharan Africa has increased between 2011- 2016 [35]. As Asians tend to have a poorer prognosis with untreated CHB [6 16 22], the changing epidemiology pattern will lead to an overall higher disease progression rate in the cohort, thus a smaller ICER of scale-up of the CHB care cascade. Second, the cost of $\mathrm{CHB}$ care cascade could be overestimated with the assumption that people in the cohort received an infinite course of antiviral treatment. Growing evidence suggests discontinuation of nucleos $(\mathrm{t})$ ide analogue is possible for some people and future guidelines may consider a finite-course treatment for subgroups of people living with CHB [36]. Additionally, our model does not specifically include the scenario of $\mathrm{CHB}$ cure, which would be expected to reduce long-term costs due to finite curative treatment, albeit with greater initial up-front costs whilst the new drugs remain under patent [30 37].

There are several limitations of this study. Our estimation of the change of current rates of testing, linking to care and treatment initiation were based on data from 2015-2017, and the actual trend may be different over time. However, a broad range of rates were considered and tested in sensitivity analysis. Our model was a simplified simulation of the natural history of $\mathrm{CHB}$ without considering HBV e antigen or HBV-DNA levels of individuals in the cohort. However, disease progression parameters sourced from clinical studies targeting subgroups of people living with $\mathrm{CHB}$ were considered in the range and tested in sensitivity analysis. For disease progression parameters, as most data were from studies involved in Asian population, the 
estimated relative risks of progressing to $\mathrm{HCC}$ from $\mathrm{CHB}$ or $\mathrm{CC}$ in African or Aboriginal and Torres Strait Islanders compared to Asians were mainly based on reviews comparing population in different continents[21 22]. However, a broad range of disease progression parameters including studies conducted in different sub-populations were tested in sensitivity analysis. Finally, this study used a simplified linear scale-up approach to care cascade progression rates for different scenarios, while in the real world the actual change is likely to be more complicated. Our approach requires a short-term prioritisation of HBV-related care in the early years of investment, which could potentially pose a challenge for strategy implementation. While this is one approach of care cascade scale-up to achieve the targets, further modelling studies are needed to inform the optimal scale-up method.

\section{CONCLUSION}

For Australia to reach the National Hepatitis B Strategy 2022 targets or WHO 2030 targets requires investment to improve all steps in the hepatitis B care cascade. Our results suggest that an immediate and substantial scale-up of the $\mathrm{CHB}$ care cascade is required if Australia is to meet the national and international targets of eliminating $\mathrm{CHB}$ as a major public health threat. Moreover, we found that it would be cost-effective to spend up to $A \$ 328$ million or $A \$ 538$ million per year (up to 2030) on implementation activities beyond direct medical costs to achieve the WHO and National Strategy targets, respectively. The key challenge will be to build community support and political will to fund this investment.

\section{REFERENCES}

1. Razavi-Shearer D, Gamkrelidze I, Nguyen $\mathrm{MH}$, et al. Global prevalence, treatment, and prevention of hepatitis $\mathrm{B}$ virus infection in 2016: a modelling study. The Lancet Gastroenterology \& Hepatology 2018;3(6):383-403 doi: 10.1016/S2468-1253(18)30056-6[published Online First: Epub Date]|.

2. WHO. Global hepatitis report, 2017 [Internet]. Geneva: World Health Organization, 2017.

3. Liaw YF. Natural History of Chronic Hepatitis B Virus Infection. In: Howard C. Thomas BSc P, FRCP, FRCPath, FMedSci, Anna S.F. Lok MD, Stephen A. Locarnini MBBS BH, PhD, FRCPath,,, Arie J. Zuckerman MD D, FRCP, FRCPath, FMedSci,, eds. Viral Hepatitis. 4 ed, 2013.

4. El-Serag HB. Epidemiology of viral hepatitis and hepatocellular carcinoma. Gastroenterology 2012;142(6):1264-73 e1 doi: 10.1053/j.gastro.2011.12.061[published Online First: Epub Date]|.

5. Papatheodoridis GV, Chan HL, Hansen BE, Janssen HL, Lampertico P. Risk of hepatocellular carcinoma in chronic hepatitis B: assessment and modification with current antiviral therapy. J Hepatol 2015;62(4):956-67 doi: 10.1016/j.jhep.2015.01.002[published Online First: Epub Date]|.

6. European Association for the Study of the Liver. EASL 2017 Clinical Practice Guidelines on the management of hepatitis B virus infection. Journal of Hepatology 2017;67:29 
7. Terrault NA, Bzowej NH, Chang KM, et al. AASLD guidelines for treatment of chronic hepatitis B. Hepatology 2016;63(1):261-83 doi: 10.1002/hep.28156[published Online First: Epub Date]|.

8. Digestive Health Foundation, Gastroenterological Society of Australia. Australian and New Zealand Chronic Hepatitis $B$ (CHB) Recommendations 2ND Edition 2009/10. Secondary Australian and New Zealand Chronic Hepatitis B (CHB) Recommendations 2ND Edition 2009/10 2010. https://www.gesa.org.au/resources/clinical-guidelines-andupdates/chronic-hepatitis-b/.

9. MacLachlan J, Thomas L, Cowie B, Allard N. Hepatitis B Mapping Project: Estimates of geographic diversity in chronic hepatitis B prevalence, diagnosis, monitoring and treatment - National Report 2017. 4 ed, 2019.

10. Romero N, McCulloch K, Allard N, JH M, BC C. National Surveillance for Hepatitis B Indicators: Measuring the progress towards the targets of the National Hepatitis B Strategy - Annual Report 2017. Melbourne: WHO Collaborating Centre for Viral Hepatitis, The Doherty Institute, 2019.

11. Kirby Institute. National Blood-borne Viruses and Sexually Transmissible Infections Surveillance and Monitoring Report, 2018. 2018

12. WHO. Global Health Sector Strategy on Viral Hepatitis 2016-2021, 2016.

13. Department of Health. Third National Hepatitis B Strategy 2018-2022, 2018.

14. McCulloch K, Romero N, MacLachlan J, Allard N, Cowie B. Modelling progress towards elimination of hepatitis B in Australia. Hepatology 2019 doi: 10.1002/hep.30899[published Online First: Epub Date]|.

15. AlHW. Cancer data in Australia, 2018.

16. Hong TP, Gow PJ, Fink M, et al. Surveillance improves survival of patients with hepatocellular carcinoma: a prospective population-based study. Med J Aust 2018;209(8):348-54

17. MacLachlan J, Thomas L, Cowie B, Allard N. Hepatitis B Mapping Project: Estimates of geographic diversity in chronic hepatitis B prevalence, diagnosis, monitoring and treatment - National Report 2016. 4 ed, 2018.

18. STEPHEN DANIEL B. Community Approach Targeting Cirrhosis and Hepatocellular carcinoma - CATCH. Monash University, 2019

19. Bell SJ, Lau A, Thompson A, et al. Chronic hepatitis B: recommendations for therapy based on the natural history of disease in Australian patients. J Clin Virol 2005;32(2):122-7 doi: 10.1016/j.jcv.2004.10.009[published Online First: Epub Date]l.

20. McCulloch K. HBV Model Data requested updated (Email communication), 2019.

21. Fattovich G, Bortolotti F, Donato F. Natural history of chronic hepatitis $B$ : special emphasis on disease progression and prognostic factors. J Hepatol 2008;48(2):335-52 doi: 10.1016/j.jhep.2007.11.011[published Online First: Epub Date]|.

22. Raffetti E, Fattovich G, Donato F. Incidence of hepatocellular carcinoma in untreated subjects with chronic hepatitis B: a systematic review and meta-analysis. Liver Int 2016;36(9):1239-51 doi: 10.1111/liv.13142[published Online First: Epub Date]l.

23. Lin X, Robinson NJ, Thursz M, et al. Chronic hepatitis B virus infection in the Asia-Pacific region and Africa: review of disease progression. J Gastroenterol Hepatol 2005;20(6):833-43 doi: 10.1111/j.1440-1746.2005.03813.x[published Online First: Epub Date]|

24. Department of Health. Pharmaceutical Benefits Scheme (PBS). Secondary Pharmaceutical Benefits Scheme (PBS) 2018. http://www.pbs.gov.au/pbs/home.

25. Department of Health. MBS Online. Secondary MBS Online 13 December 20182018 http://www.mbsonline.gov.au/internet/mbsonline/publishing.nsf/Content/Home.

26. Pharmaceutical Benefits Advisory Committee. Guidelines for preparing a submission to the Pharmaceutical Benefits Advisory Committee (version 5.0). In: Australian Government Department of Health, ed., 2016.

27. Nguyen NH, Nguyen V, Trinh HN, Lin B, Nguyen MH. Treatment eligibility of patients with chronic hepatitis B initially ineligible for therapy. Clin Gastroenterol Hepatol 2013;11(5):565-71 doi: 10.1016/j.cgh.2012.12.028[published Online First: Epub Date]|.

28. Uribe LA, Nguyen N, Kim L, et al. Rates of Treatment Eligibility in Follow-Up of Patients with Chronic Hepatitis B (CHB) Across Various Clinical Settings Who Were Initially Ineligible at Presentation. Dig Dis Sci 2016;61(2):618-25 doi: 10.1007/s10620-015-3982-4[published Online First: Epub Date]|.

29. Lieveld FI, van Vlerken LG, Siersema PD, van Erpecum KJ. Patient adherence to antiviral treatment for chronic hepatitis B and C: a systematic review. Annals of hepatology 2013;12(3):380-91 
30. Nayagam S, Thursz M, Sicuri E, et al. Requirements for global elimination of hepatitis B: a modelling study. The Lancet Infectious Diseases 2016;16(12):1399-408 doi: 10.1016/s1473-3099(16)30204-3[published Online First: Epub Date]|.

31. Global Burden of Disease Collaborative Network. Global Burden of Disease Study 2017 (GBD 2017) Disability Weights. Secondary Global Burden of Disease Study 2017 (GBD 2017) Disability Weights 2018. http://ghdx.healthdata.org/gbd-2017.

32. Hill A, Gotham D, Cooke G, et al. Analysis of minimum target prices for production of entecavir to treat hepatitis B in highand low-income countries. Journal of virus eradication 2015;1(2):103-10

33. Australian Institute of Health and Welfare. Health expenditure Australia 2016-17. Health and welfare expenditure series no. 64. Cat. no. HWE 74. Canberra: AlHW, 2018.

34. Scalone L, Fagiuoli S, Ciampichini R, et al. The societal burden of chronic liver diseases: results from the COME study. BMJ Open Gastroenterol 2015;2(1):e000025 doi: 10.1136/bmjgast-2014-000025[published Online First: Epub Date]|

35. MacLachlan JH, Cowie BC. Cultural and linguistic diversity of people living with chronic hepatitis B in 2011-2016: changing migration, shifting epidemiology. Aust N Z J Public Health 2018;42(5):441-43 doi: 10.1111/17536405.12826[published Online First: Epub Date]|.

36. Liaw Y-F. Stop-and-watch strategy after cessation of nucleos(t)ide analogue therapy in HBeAg-negative patients. Journal of Hepatology 2018;68(5):1102-04 doi: 10.1016/j.jhep.2017.12.031[published Online First: Epub Date]|.

37. Lok AS, Zoulim F, Dusheiko G, Ghany MG. Hepatitis B cure: From discovery to regulatory approval. Hepatology (Baltimore, Md.) 2017;66(4):1296-313 doi: 10.1002/hep.29323[published Online First: Epub Date]|.

38. Shimakawa Y, Lemoine M, Njai HF, et al. Natural history of chronic HBV infection in West Africa: a longitudinal populationbased study from The Gambia. Gut 2016;65(12):2007-16 doi: 10.1136/gutjnl-2015-309892[published Online First: Epub Date]|.

39. Poh Z, Goh BB, Chang PE, Tan CK. Rates of cirrhosis and hepatocellular carcinoma in chronic hepatitis B and the role of surveillance: a 10-year follow-up of 673 patients. Eur J Gastroenterol Hepatol 2015;27(6):638-43 doi: 10.1097/meg.0000000000000341[published Online First: Epub Date]|

40. Chu CM, Liaw YF. Hepatitis B surface antigen seroclearance during chronic HBV infection. Antivir Ther 2010;15(2):133-43 doi: 10.3851/imp1497[published Online First: Epub Date]|.

41. Zhou K, Contag C, Whitaker E, Terrault N. Spontaneous loss of surface antigen among adults living with chronic hepatitis $B$ virus infection: a systematic review and pooled meta-analyses. The Lancet Gastroenterology \& Hepatology 2019 doi: https://doi.org/10.1016/S2468-1253(18)30308-X[published Online First: Epub Date]|.

42. Chen Y-C, Chu C-M, Yeh C-T, Liaw Y-F. Natural course following the onset of cirrhosis in patients with chronic hepatitis B: a long-term follow-up study. Hepatology International 2007;1(1):267-73 doi: 10.1007/s12072-007-5001-0[published Online First: Epub Date]|

43. Nayagam S, Conteh L, Sicuri E, et al. Cost-effectiveness of community-based screening and treatment for chronic hepatitis B in The Gambia: an economic modelling analysis. The Lancet Global Health 2016;4(8):e568-e78 doi: 10.1016/S2214-109X(16)30101-2[published Online First: Epub Date].

44. Tong MJ, Hsien C, Song JJ, et al. Factors associated with progression to hepatocellular carcinoma and to death from liver complications in patients with HBsAg-positive cirrhosis. Dig Dis Sci 2009;54(6):1337-46 doi: 10.1007/s10620-0090747-y[published Online First: Epub Date]|.

45. Marcellin P, Gane E, Buti M, et al. Regression of cirrhosis during treatment with tenofovir disoproxil fumarate for chronic hepatitis B: a 5-year open-label follow-up study. Lancet (London, England) 2013;381(9865):468-75 doi: 10.1016/s0140-6736(12)61425-1[published Online First: Epub Date]|.

46. Wong GL, Chan HL, Mak CW, et al. Entecavir treatment reduces hepatic events and deaths in chronic hepatitis $B$ patients with liver cirrhosis. Hepatology 2013;58(5):1537-47 doi: 10.1002/hep.26301[published Online First: Epub Date]|.

47. Shim JH, Lee HC, Kim KM, et al. Efficacy of entecavir in treatment-naïve patients with hepatitis $B$ virus-related decompensated cirrhosis. Journal of Hepatology 2010;52(2):176-82 doi: https://doi.org/10.1016/j.jhep.2009.11.007[published Online First: Epub Date]|.

48. European Association for the Study of the Liver. Electronic address eee, European Association for the Study of the L. EASL Clinical Practice Guidelines for the management of patients with decompensated cirrhosis. J Hepatol 2018;69(2):40660 doi: 10.1016/j.jhep.2018.03.024[published Online First: Epub Date]|. 
49. Wallace MC, Preen DB, Short MW, Adams LA, Jeffrey GP. Hepatocellular carcinoma in Australia 1982-2014: Increasing incidence and improving survival. Liver Int 2019;39(3):522-30 doi: 10.1111/liv.13966[published Online First: Epub Date]|.

50. Wigg AJ, Chin JK, Muller KR, Ramachandran J, Woodman RJ, Kaambwa B. Cost-effectiveness of a chronic disease management model for cirrhosis: Analysis of a randomized controlled trial. J Gastroenterol Hepatol 2018 doi: 10.1111/jgh.14127[published Online First: Epub Date]|.

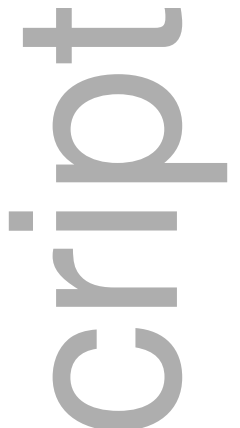

Tables

Table 1. Inputs of disease progression parameters after calibration

\begin{tabular}{|c|c|c|c|c|}
\hline \multicolumn{2}{|c|}{ Disease progression probabilities } & Estimate & $\begin{array}{l}\text { PSA } \\
\text { parameters }\end{array}$ & $\begin{array}{l}\text { Referenc } \\
\text { e }\end{array}$ \\
\hline \multirow[t]{6}{*}{$\begin{array}{l}\text { Natural } \\
\text { history }\end{array}$} & Annual rate of transition from $\mathrm{CHB}$ to $\mathrm{CC}$ & $1.51 \%(0.05 \%-4.85 \%)$ & $\begin{array}{l}\alpha=1.44 \\
\beta=46.36\end{array}$ & {$[21]$} \\
\hline & Annual rate of transition from $\mathrm{CHB}$ to $\mathrm{HCC}^{\dagger}$ & $0.20 \%(0.13 \%-0.58 \%)$ & $\begin{array}{l}\alpha=2.93 \\
\beta=741.03\end{array}$ & $\begin{array}{l}{\left[\begin{array}{ll}21 & 2238 \\
39]\end{array}\right.}\end{array}$ \\
\hline & Annual rate of sAg seroclearnce from $\mathrm{CHB}^{\ddagger}$ & $0.64 \%(0.39 \%-0.92 \%)$ & $\begin{array}{l}\alpha=22.10 \\
\beta=1704.41\end{array}$ & [40 41] \\
\hline & Annual rate of transition from CC to DC & $1.53 \%(0.75 \%-2.30 \%)$ & $\begin{array}{l}\alpha=14.39 \\
\beta=457.43\end{array}$ & {$\left[\begin{array}{lll}21 & 23 & 42\end{array}\right]$} \\
\hline & Annual rate of transition from $\mathrm{CC}$ to $\mathrm{HCC}^{\dagger}$ & $1.23 \%(0.51 \%-2.41 \%)$ & $\begin{array}{l}\alpha=6.27 \\
\beta=248.04\end{array}$ & {$\left[\begin{array}{lll}21 & 22 & 39\end{array}\right]$} \\
\hline & Annual rate of transition from DC to HCC & $3.55 \%(1.15 \%-5.95 \%)$ & $\begin{array}{l}\alpha=7.74 \\
\beta=101.24\end{array}$ & {$\left[\begin{array}{lll}23 & 43 & 44\end{array}\right]$} \\
\hline \multirow[t]{4}{*}{$\begin{array}{l}\text { Under } \\
\text { NAs }\end{array}$} & Annual rate of transition from $\mathrm{CHB}$ to $\mathrm{CC}$ & $0.12 \%(0.12 \%-0.30 \%)$ & $\begin{array}{l}\alpha=6.74 \\
\beta=2801.25\end{array}$ & [45] \\
\hline & Annual rate of transition from $\mathrm{CHB}$ to $\mathrm{HCC}^{\dagger}$ & $0.04 \%(0.03 \%-0.12 \%)$ & $\begin{array}{l}\alpha=2.94 \\
\beta=3732.64\end{array}$ & $\begin{array}{lll}{\left[\begin{array}{lll}5 & 21 & 22 \\
38 & 39\end{array}\right]}\end{array}$ \\
\hline & Annual rate of sAg seroclearance from $\mathrm{CHB}$ & $1.87 \%(0.00 \%-2.70 \%)$ & $\begin{array}{l}\alpha=7.07 \\
\beta=181.85\end{array}$ & {$\left[\begin{array}{ll}6 & 45\end{array}\right]$} \\
\hline & Annual rate of transition from CC to DC & $0.50 \%(0.45 \%-1.90 \%)$ & $\begin{array}{l}\alpha=1.80 \\
\beta=178.09\end{array}$ & {$[46]$} \\
\hline
\end{tabular}




\begin{tabular}{|c|c|c|c|}
\hline Annual rate of transition from $\mathrm{CC}$ to $\mathrm{HCC}^{\dagger}$ & $0.68 \%(0.28 \%-1.69 \%)$ & $\begin{array}{l}\alpha=3.50 \\
\beta=254.58\end{array}$ & {$[5$ 46] } \\
\hline Annual rate of transition from DC to $\mathrm{HCC}$ & $2.17 \%(1.85 \%-2.49 \%)$ & $\begin{array}{l}\alpha=6.70 \\
\beta=132.91\end{array}$ & {$\left[\begin{array}{lllllll}5 & 4 & 47\end{array}\right]$} \\
\hline \multicolumn{4}{|l|}{ Probability of HBV-related death } \\
\hline Annual probability of dying in CC & $1.65 \%(1.45 \%-4.00 \%)$ & $\begin{array}{l}\alpha=6.19 \\
\beta=131.34\end{array}$ & {$\left[\begin{array}{lll}21 & 23 & 42\end{array}\right]$} \\
\hline Annual probability of dying in CC (antiviral therapy) & $0.21 \%(0.05 \%-1.04 \%)$ & $\begin{array}{l}\alpha=0.72 \\
\beta=166.15\end{array}$ & {$[4546]$} \\
\hline Annual probabili & $15.7 \%(2.15 \%-28.5 \%)$ & $\begin{array}{l}\alpha=3.43 \\
\beta=7.49\end{array}$ & {$[2343]$} \\
\hline Annual probability of dying in DC (antiviral therapy) & $12.56 \%(2.15 \%-28.5 \%)$ & $\begin{array}{l}\alpha=2.36 \\
\beta=7.04\end{array}$ & {$[4748]$} \\
\hline Annual probability of dying in HCC & $35.0 \%(20 \%-50 \%)$ & $\begin{array}{l}\alpha=5.57 \\
\beta=2.39\end{array}$ & {$\left[\begin{array}{llll}15 & 23 & 43\end{array}\right]$} \\
\hline Annual probability of dying in HCC (antiviral therapy) & $17.5 \%(3.5 \%-50 \%)$ & $\begin{array}{l}\alpha=1.06 \\
\beta=1.98\end{array}$ & {$[49]$} \\
\hline \multicolumn{4}{|c|}{$\begin{array}{l}\mathrm{NA}=\text { Nucleos }(\mathrm{t}) \text { ide analogs. } \mathrm{CHB}=\text { Chronic hepatitis } \mathrm{B} . \mathrm{CC}=\text { Compensated cirrhosis. } \mathrm{DC}=\text { Decompensated } \\
\text { cirrhosis. } \mathrm{HCC}=\text { Hepatocellular carcinoma. } \mathrm{HBV}=\text { Hepatitis } \mathrm{B} \text { virus. } \mathrm{PSA}=\text { probabilistic sensitivity analysis (beta } \\
\text { distribution for parameters in this table) } \\
\dagger \text { Adjusted for age, gender and ethnicity composition. } \\
\text { ‡Weighted by age. }\end{array}$} \\
\hline
\end{tabular}


Table 2. Inputs of direct medical costs and disability weight in CHB related health states and care cascade statuses.

\begin{tabular}{|c|c|c|c|c|c|c|}
\hline $\begin{array}{l}\text { Disease } \\
\text { management status }\end{array}$ & $\begin{array}{l}\text { Health } \\
\text { states }\end{array}$ & $\begin{array}{l}\text { Base } \\
\text { case }\end{array}$ & $\begin{array}{l}\text { Lower } \\
\text { bound }\end{array}$ & $\begin{array}{l}\text { Upper } \\
\text { bound }\end{array}$ & Reference & Explanatory notes \\
\hline \multicolumn{7}{|l|}{ Direct medical costs } \\
\hline $\begin{array}{l}\text { Diagnosed with } \\
\text { CHB but not in } \\
\text { care }\end{array}$ & $\mathrm{CHB}$ & $\$ 112$ & $\$ 87$ & $\$ 141$ & MBS (Dec 2018) [25] & Once-off cost \\
\hline $\begin{array}{l}\text { In care (not } \\
\text { receiving } \\
\text { treatment) }\end{array}$ & $\mathrm{CHB}$ & $\$ 557$ & $\$ 441$ & $\$ 887$ & MBS (Dec 2018) [25] & \\
\hline \multirow{4}{*}{$\begin{array}{l}\text { In care (on } \\
\text { treatment) }\end{array}$} & $\mathrm{CHB}$ & $\$ 3,985$ & $\$ 799$ & $\$ 6,198$ & MBS, PBS (May 2019) [24 25] & $\begin{array}{l}\text { Cost range was estimated from MBS, PBS and drug costs in hospitals, } \\
\text { online pharmacy stores. }\end{array}$ \\
\hline & CC & $\$ 4,165$ & $\$ 979$ & $\$ 7,752$ & MBS, PBS (May 2019) [24 25] & \\
\hline & $\mathrm{DC}$ & $\$ 20,061$ & $\$ 9,247$ & $\$ 30,875$ & Estimation & $\begin{array}{l}\text { Estimated from the costs of chronic liver failure management in } \\
\text { South Australia [50]. }\end{array}$ \\
\hline & HCC & $\$ 16,533$ & $\$ 8,630$ & $\$ 31,398$ & Estimation & $\begin{array}{l}\text { Estimated from unpublished data of a Melbourne HCC cohort } \\
\text { consisting of } 722 \text { patients (Hong T, 2018). }\end{array}$ \\
\hline \multicolumn{7}{|l|}{ Disability weight } \\
\hline \multirow[t]{3}{*}{ Natural history } & $\mathrm{CHB}$ & 0.051 & 0.032 & 0.074 & Assumption & DW for 'moderate acute hepatitis B' was used. \\
\hline & $\mathrm{CC}$ & 0.123 & 0.085 & 0.173 & Assumption & $\begin{array}{l}\text { DW for 'Decompensated cirrhosis (lower CI)' was used to be in } \\
\text { consistent with hep B modelling study [43] }\end{array}$ \\
\hline & $\mathrm{DC}$ & 0.178 & 0.123 & 0.25 & GBD 2017[31] & DW for 'cirrhosis and other chronic liver diseases due to hepatitis B, \\
\hline
\end{tabular}

This article is protected by copyright. All rights reserved 


\begin{tabular}{|l|l|l|l|l|l|l|}
\hline & & & & & & decompensated' was used. \\
\cline { 2 - 7 } & HCC & 0.44 & 0.193 & 0.687 & GBD 2017[31] & $\begin{array}{l}\text { The range of DW of 'diagnosis phase, metastatic and terminal phase } \\
\text { of liver cancer due to hepatitis B' was used. The base case was the } \\
\text { average of the range. }\end{array}$ \\
\hline \multirow{3}{*}{ Treated } & CHB & 0.012 & 0.006 & 0.023 & Assumption & The DW for 'Early HIV without anemia' was used as proxy. \\
\cline { 2 - 7 } & CC & 0.051 & 0.032 & 0.074 & Assumption & Assumed return to 'natural history CHB'. \\
\cline { 2 - 7 } & DC & 0.133 & 0.088 & 0.19 & Assumption & Assumed return to 'natural history CC'. \\
\cline { 2 - 7 } & HCC & 0.133 & 0.088 & 0.19 & Assumption & Assumed return to 'natural history CC'. \\
\hline Sero-clearance & 0 & 0 & 0.006 & Assumption & $\begin{array}{l}\text { The upper bound was assumed to be DW for CHB treated (lower CI } \\
\text { used). }\end{array}$ \\
\hline
\end{tabular}

$\mathrm{CHB}=$ Chronic hepatitis B. $\mathrm{CC}=$ Compensated cirrhosis. $\mathrm{DC}=$ Decompensated cirrhosis. $\mathrm{HCC}=$ Hepatocellular carcinoma. $\mathrm{HBV}=$ Hepatitis B virus. DW= Disability weight.

$\mathrm{GBD}=$ Global Burden of Disease study

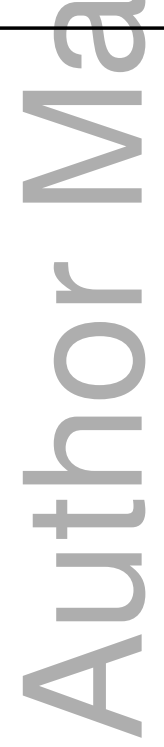

This article is protected by copyright. All rights reserved 
Table 3. Hepatitis B care continum, clinical and economic outcomes (2016-2030) of people living with chronic hepatitis B in Australia under continued current care, the $3^{\text {rd }}$ National Strategy, and WHO Strategy.

\begin{tabular}{|c|c|c|c|c|}
\hline & & Status quo & The $3^{\text {rd }}$ National Strategy & WHO Strategy \\
\hline \multirow[t]{3}{*}{$\begin{array}{l}\text { Care continuum } \\
\text { in } 2030\end{array}$} & $\begin{array}{l}\text { Diagnosed proportion among } \\
\text { people living with } \mathrm{CHB}\end{array}$ & $69 \%(64 \%-74 \%)$ & $86 \%(84 \%-88 \%)$ & $90 \%(88 \%-92 \%)$ \\
\hline & $\begin{array}{l}\text { Receiving care among people } \\
\text { living with } \mathrm{CHB}\end{array}$ & $30 \%(28 \%-40 \%)$ & $69 \%(66 \%-72 \%)$ & $85 \%(83 \%-87 \%)$ \\
\hline & $\begin{array}{l}\text { Receiving treatment among } \\
\text { diagnosed people }\end{array}$ & $18 \%(17 \%-25 \%)$ & $37 \%(35 \%-45 \%)$ & $46 \%(44 \%-56 \%)$ \\
\hline \multirow{5}{*}{$\begin{array}{l}\text { Economic outcomes } \\
(2016-2030)\end{array}$} & Costs (million Australian dollars) & $\mathrm{A} \$ 1,718(1,425-2,088)$ & $\mathrm{A} \$ 3,031(2,436-3,414)$ & $\mathrm{A} \$ 4,110(3,838-4,463)$ \\
\hline & DALYs (million) & $1.12(0.79-1.20)$ & $1.02(0.72-1.11)$ & $0.95(0.70-1.04)$ \\
\hline & $\begin{array}{l}\text { Cost difference }^{\dagger} \\
\text { (million Australian dollars) }\end{array}$ & - & $\mathrm{A} \$ 1,313(866-1,404)$ & $\mathrm{A} \$ 2,391(2,067-2,738)$ \\
\hline & DALYs averted $^{\dagger}$ & - & $97,743(50,300-108,088)$ & $165,134(90,568-183,834)$ \\
\hline & ICER (A \$ DALY averted) ${ }^{\dagger}$ & - & $A \$ 13,435(10,236-21,165)$ & $\mathrm{A} \$ 14,482(13,031-25,641)$ \\
\hline \multicolumn{2}{|c|}{$\begin{array}{l}\text { Annual value prepared to pay to maintain ICER }< \\
\text { A } \$ 50,000 / D A L Y \text { averted (million } A \$ \text { ) }\end{array}$} & & $\mathrm{A} \$ 328(139-397)$ & $\mathrm{A} \$ 538(220-639)$ \\
\hline
\end{tabular}

${ }^{\dagger}$ compared to status quo. $\mathrm{CHB}=$ Chronic hepatitis $\mathrm{B} . \mathrm{CC}=$ Compensated cirrhosis. $\mathrm{DC}=$ Decompensated cirrhosis. $\mathrm{HCC}=$ Hepatocellular carcinoma. $\mathrm{HBV}=$ Hepatitis $\mathrm{B}$ virus. $\mathrm{A} \$=$ Australian dollar. IQR was presented in parentheses if not additionally indicated.

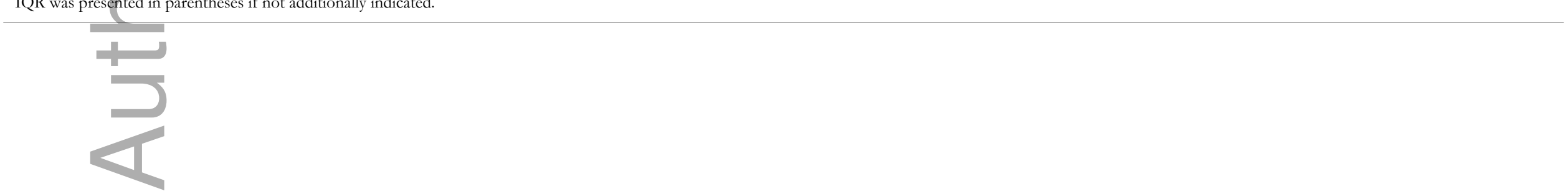

This article is protected by copyright. All rights reserved 


\section{FIGURES LEGEND}

Figure 1. Model schematics.

The model included four exclusive health states: CHB, CC, DC and HCC, and three exclusive care cascade states: Undiagnosed, Diagnosed but not in care and In care (with or without treatment). The model was initialised according to the disease and care cascade distribution in Australia in 2016. Each time step, representing one year, people could: enter the model (e.g. when migrating to Australia with CHB or becoming chronically infected with HBV); progress their disease stages (rates of disease progression were adjusted for age, sex and race/ethnicity of people living with CHB in Australia); move through the care cascade; clear their virus with surface antigen loss; or leave the model due to death.

$\mathrm{CHB}=$ chronic hepatitis $\mathrm{B} . \mathrm{CC}=$ compensated cirrhosis. $\mathrm{DC}=$ decompensated cirrhosis. $\mathrm{HCC}=$ hepatocellular carcinoma.

Figure 2. Projections of 1) diagnosed proportion, 2) linkage in care proportion, and 3) receiving treatment

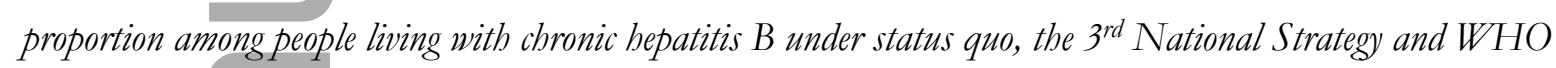
Strategy.

Figure 3. Sensitivity analysis: key parameters affect the ICERs of the 1) National Strategy and 2) WHO Strategy.

1) The impact of key parameters on the of National Strategy ICER.

2) The impact of key parameters on the WHO Strategy ICER.

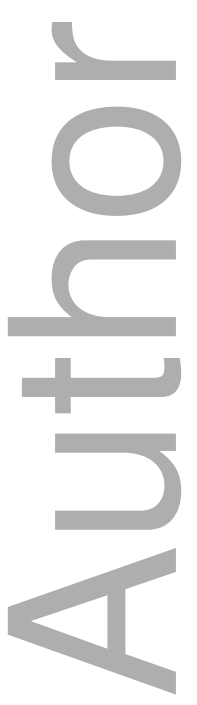




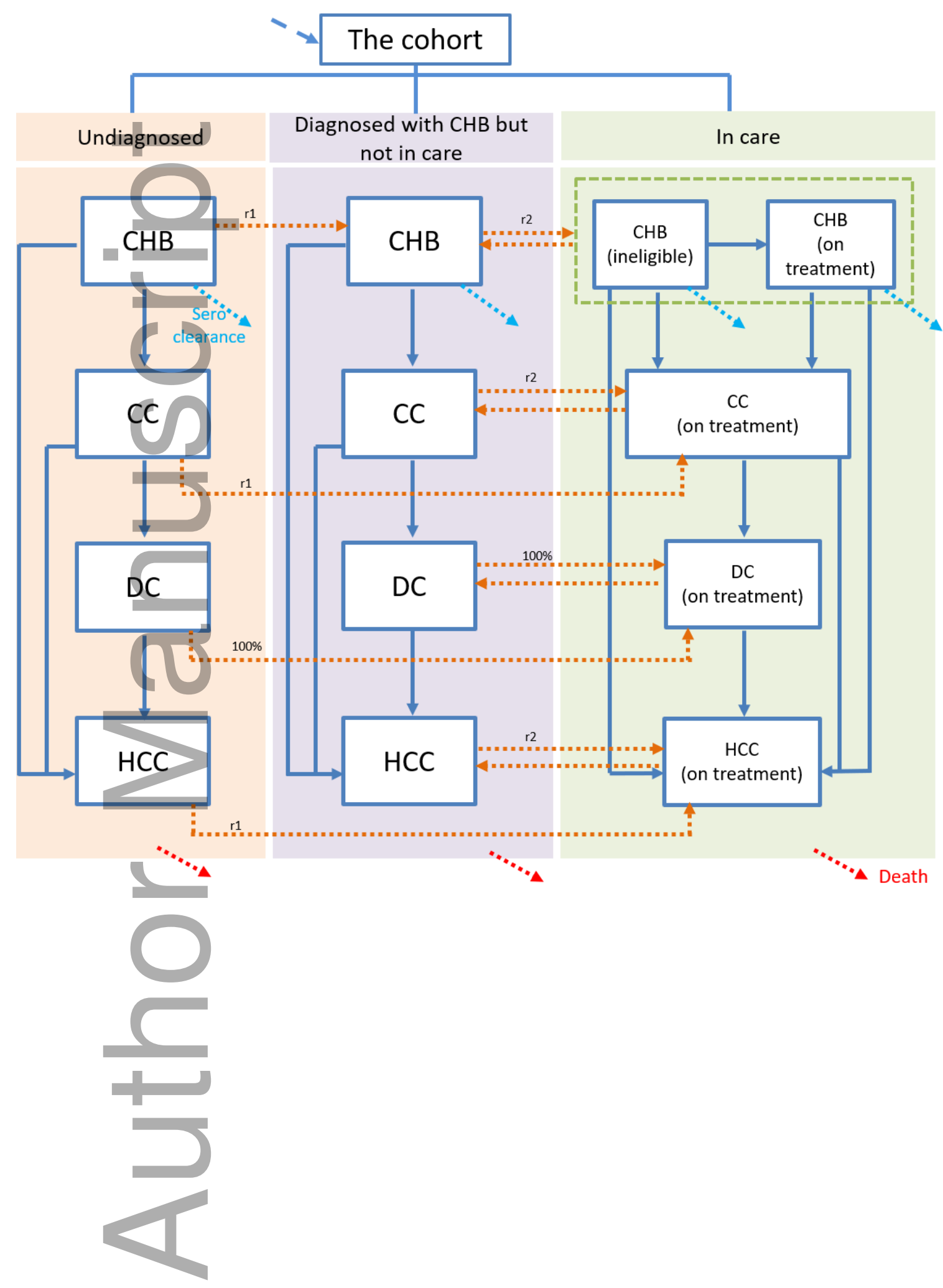

This article is protected by copyright. All rights reserved 
Figure 2. Projections of 1) diagnosed proportion, 2) linkage in care proportion, and 3) receiving treatment proportion among people living with chronic hepatitis B under status quo, the $3^{\text {rd }}$ National Strategy and WHO Strategy.

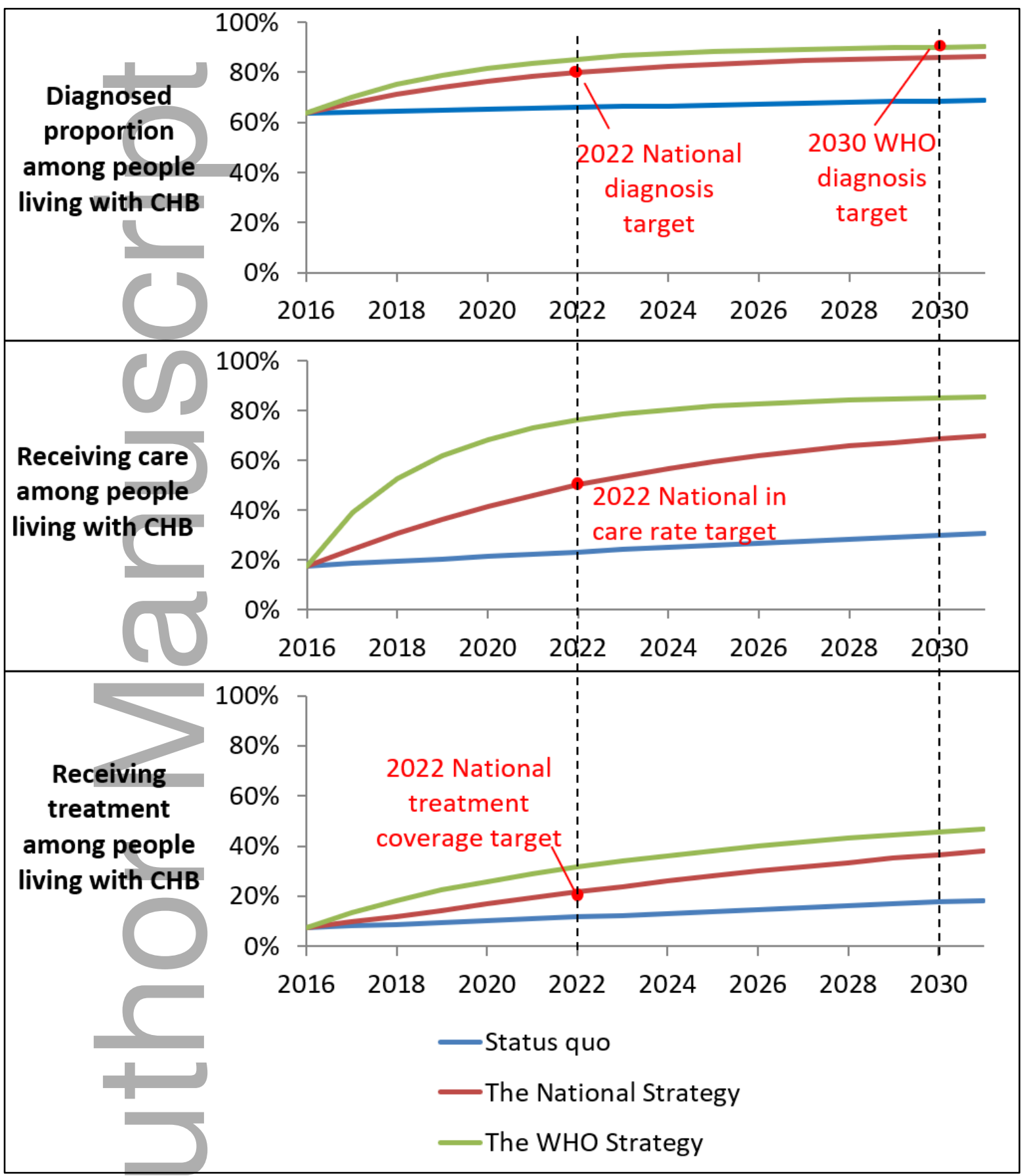

This article is protected by copyright. All rights reserved 
Figure 3. Sensitivity analysis: key parameters affect the ICERs of the 1) National Strategy and 2) WHO Strategy.

1) The impact of key parameters on the National Strategy ICER.

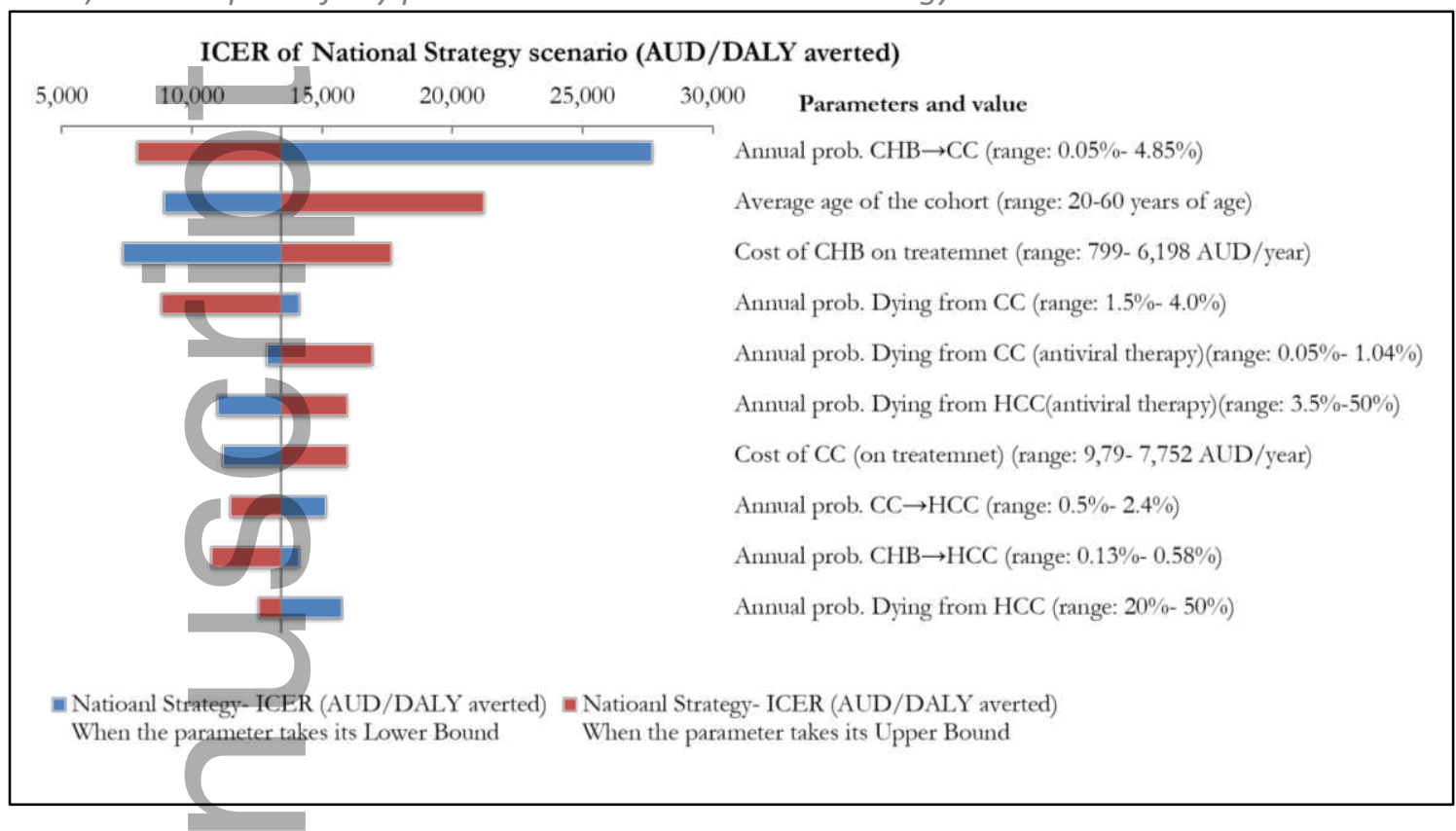

2) The impact of key parameters on the WHO Strategy ICER.

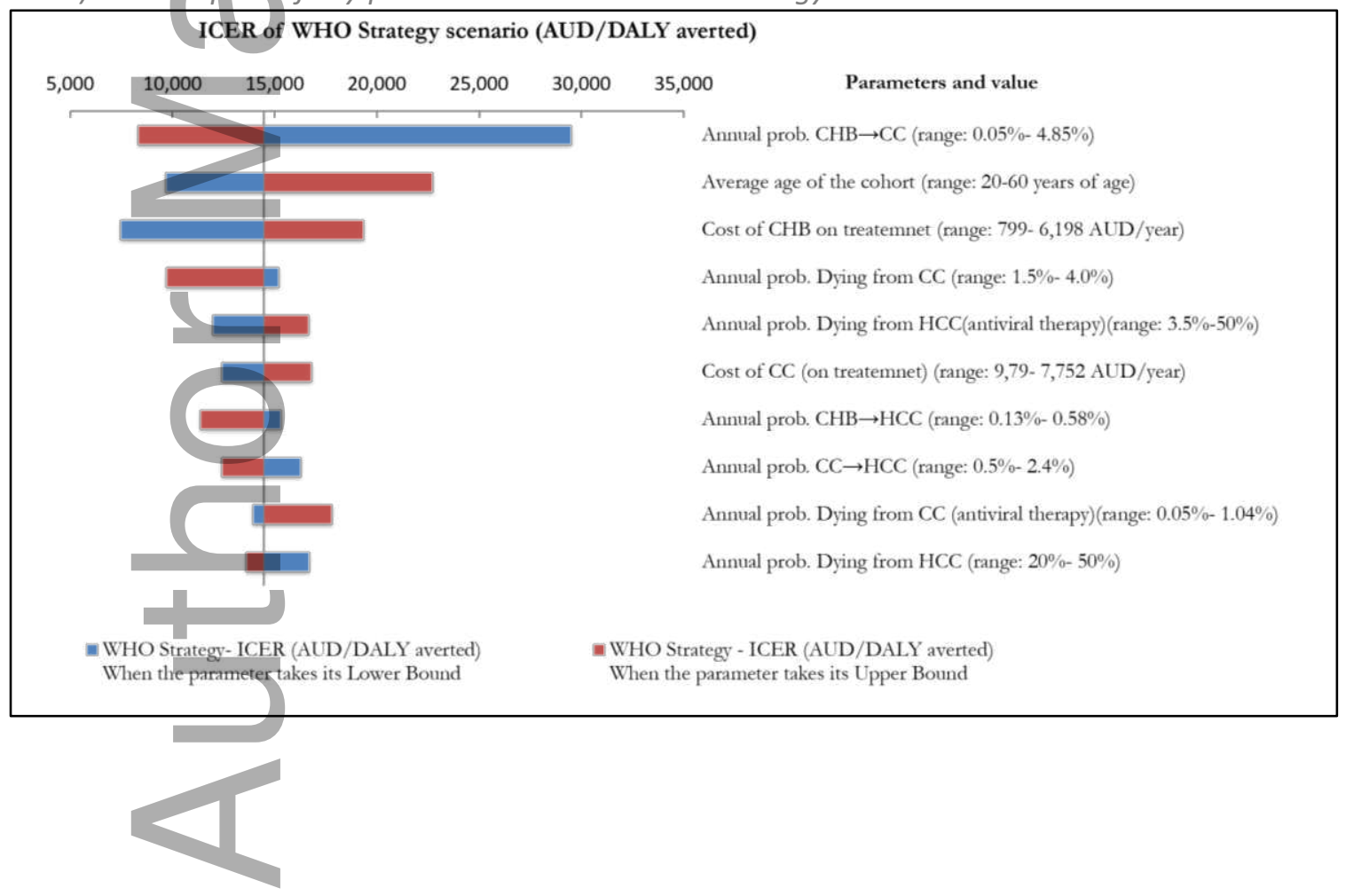




\section{University Library}

\section{- M M N E R VA A gateway to Melbourne's research publications}

Minerva Access is the Institutional Repository of The University of Melbourne

Author/s:

Xiao, Y;Howell, J;van Gemert, C;Thompson, AJ;Seaman, CP;McCulloch, K;Scott, N;Hellard, $\mathrm{ME}$

Title:

Enhancing the hepatitis B care cascade in Australia: A cost-effectiveness model

Date:

2020-01-03

Citation:

Xiao, Y., Howell, J., van Gemert, C., Thompson, A. J., Seaman, C. P., McCulloch, K., Scott, N. \& Hellard, M. E. (2020). Enhancing the hepatitis B care cascade in Australia: A cost-effectiveness model. JOURNAL OF VIRAL HEPATITIS, 27 (5), pp.526-536. https:// doi.org/10.1111/jvh.13252.

Persistent Link:

http://hdl.handle.net/11343/275236 